University of South Florida

DIGITAL COMMONS

Digital Commons @ University of

@ UNIVERSITY OF SOUTH FLORIDA

South Florida

Rehabilitation and Mental Health Counseling

Faculty Publications

Rehabilitation and Mental Health Counseling

$1-2008$

\title{
Ultra Wideband Radio: A Novel Method for Measuring Wandering in Persons with Dementia
}

\author{
William D. Kearns \\ University of South Florida, kearns@usf.edu \\ Donna Algase \\ University of Michigan \\ D. Helen Moore \\ James A. Haley Veterans Administration Hospital \\ Sadia Ahmed \\ University of South Florida
}

Follow this and additional works at: https://digitalcommons.usf.edu/mhs_facpub

\section{Scholar Commons Citation}

Kearns, William D.; Algase, Donna; Moore, D. Helen; and Ahmed, Sadia, "Ultra Wideband Radio: A Novel Method for Measuring Wandering in Persons with Dementia" (2008). Rehabilitation and Mental Health Counseling Faculty Publications. 141.

https://digitalcommons.usf.edu/mhs_facpub/141

This Article is brought to you for free and open access by the Rehabilitation and Mental Health Counseling at Digital Commons @ University of South Florida. It has been accepted for inclusion in Rehabilitation and Mental Health Counseling Faculty Publications by an authorized administrator of Digital Commons @ University of South Florida. For more information, please contact digitalcommons@usf.edu. 


\title{
Ultra wideband radio: A novel method for meas- uring wandering in persons with dementia
}

\author{
William D. Kearns PhD \\ Department of Aging and Mental Health \\ Louis de la Parte Florida Mental Health Institute \\ University of South Florida, Tampa, FL 33612, USA \\ E: kearns@fmhi.usf.edu \\ Donna Algase RN, PhD \\ University of Michigan School of Nursing, Ann Arbor, Michigan, \\ USA \\ D. Helen Moore PhD \\ James A. Haley Veterans Administration Hospital \\ Patient Safety Center of Inquiry, Tampa, Florida, USA

\section{Sadia Ahmed} \\ Department of Electrical Engineering

W.D. Kearns, D. Algase, D.H. Moore, S. Ahmed. Ultra wideband radio: A novel method for measuring wandering in persons with dementia. Gerontechnology 2008; 7(1):48-57. Wandering by persons with dementia is a complex syndrome of locomotive behaviors shaped by environmental, wanderer-specific and caregiver characteristics that vary the risk level for exiting, elopement, getting lost and accidental death. While valid and reliable methods to measure wandering exist, few have been evaluated for measurement of specific geographical patterns of wandering behavior as they occur in space and over time. In this paper we demonstrate how UWB-RFID can be used to unobtrusively and continuously measure two particularly high-risk wandering behaviors over intervals from weeks to months that occur in proximity to care setting exit points: lingering near exit doorways and shadowing (closely trailing behind) others who may exit.

\section{Keywords: wandering, dementia, observation methods, shadowing, lingering}

Accurate measurement of locomotion can inform our understanding of wandering, one of the most prevalent, problematic and high-risk dementia-related behaviors. This paper presents results from lab tests examining ultra wideband radio's ability to yield valid and reliable data on normal healthy volunteers who simulated two wandering behaviors, 'lingering' or waiting near exit doorways, and 'shadowing' or trailing closely behind a caregiver. These behaviors are important because they occur commonly in dementia care settings (nursing homes, adult living facilities and private family homes), and have been reported anecdotally to be precursors or antecedents to wanderers exiting these settings. An increased understanding of lingering and shadowing holds promise for informing design of earlier and more effective intervention and management strategies to prevent unwanted exits by persons with dementia.

The aims of the paper are to: (i) define dementing disorders, wandering and wandering outcomes; (ii) describe measurement approaches to wandering; (iii) 
provide a descriptive overview of Radio Frequency Identification and Ultra Wideband Radio Devices (UWB-RFID); (iv) provide evidence of UWB-RFID's fit with lingering and shadowing studies; (v) present lab-based proof of concept data, and (vi) discuss future research.

\section{Definition AND OUtComes}

Dementia is caused by disorders of the brain and is associated with deterioration of memory, concentration and judgment serious enough to interfere with activities of daily living ${ }^{1}$. Dementia affects $5-8 \%$ of all people between ages 65 and 74, up to $20 \%$ of those between 75 and 84 , and $30-47 \%$ of those aged $85+$. Alzheimer's disease (AD) accounts for $50-60 \%$ of all dementias. Five million Americans have $\mathrm{AD}$; that number is expected to grow to as many as 16 million by the middle of the twenty-first century as the population as a whole ages ${ }^{2}$.

Although wandering affects up to $60 \%$ of persons with dementia, this behavior has historically been difficult to define. Offered from the multiple perspectives of various disciplines and stakeholders, the literature is replete with often conflicting and confounding definitions of wandering. Recently, a comprehensive, integrated definition of dementia-related wandering was proposed to guide knowledge development across fields. Accordingly, wandering is a "...syndrome of dementiarelated locomotion behavior having a frequent, repetitive, temporally-disordered and/or spatially-disoriented nature that is manifested in lapping, random and/or pacing patterns, some of which are associated with eloping, eloping attempts, or getting lost unless accompanied ${ }^{\prime 3}$. We favor the foregoing definition of wandering because its components are verifiable and delineate associated patient health and safety risks.

Wandering is often a discomforting and high-risk behavior for wanderers, their caregivers, other residents/occupants of a care setting, health care staff/administrators and society at large. While beneficial outcomes of wandering such as exercise are sometimes discussed ${ }^{4}$, the literature more typically associates wandering with adverse events including falls, accidents, fractures and other injuries, hindered eating, weight loss, fatigue, sleep disturbances, berating and abuse, getting lost, and untimely death ${ }^{5-8}$. Unwanted exiting is probably the most hazardous outcome of wandering; nearly half of 104 communityresiding dementia patients in one study made an unwanted exit or eloped at least once and, for those who did, risk of institutionalization was very high ${ }^{9}$. As a highrisk behavior, wandering heavily burdens wanderers themselves (increased likelihood of abuse $\mathrm{e}^{10}$ and restraint use $)^{11}$; caregivers (increased need for surveillance of wandering behavior and redirecting and retrieving lost wanderers); co-residents (increased incidence of wanderer invasion into personal space ${ }^{12}$ ); health care systems (increased cost of care ${ }^{13}$ and vulnerability to negligence lawsuits) ${ }^{14}$; and for society at large (increased use of public funds for institutional care $)^{15}$.

\section{MeAsurement APPROACHES}

Over time, researchers have developed a range of measurement methods to study wandering that vary by research goals and contexts. Likewise, supporting information concerning the validity and reliability of such measurement methods is highly variable, often due to investigators' failure to specify wandering on a conceptual or definitional basis. In a number of studies, no psychometric properties of wandering measures are reported, while some other methodological studies provide full psychometric evaluation of purpose-specific wandering measures. Major approaches to wandering measurement relate to type of measure, context where applied, existence of validity and reliability information, relationship to the definition of wandering presented at the beginning of this paper, 
Table 1. Major measurement methods for wandering; $N H=$ Nursing home; ALF = Assisted living facility; ${ }^{\infty}=$ Device reliability established by manufacturer; reliability of readings affected by research procedures; ${ }^{+}=$Indirect observation to detect and record data; ${ }^{\S}=$ Validity varies according to coding scheme used for wandering

\begin{tabular}{|c|c|c|c|c|}
\hline Instrument & Context & Validity & Reliability & Facets addressed \\
\hline \multirow[t]{3}{*}{ Algase wandering scale } & $\mathrm{NH}, \mathrm{ALF}^{16,17}$ & Construct & Internal & Frequency repetition \\
\hline & Community & Convergent & consistency & Temporal distribution \\
\hline & & criterion & test-retest & Spatial disorientation \\
\hline \multirow{2}{*}{$\begin{array}{l}\text { StepWatch }{ }^{18,19} \text { activity } \\
\text { monitor }\end{array}$} & $\mathrm{NH}$ & Criterion & $\mathrm{n} / \mathrm{a}^{\infty}$ & Frequency \\
\hline & & & & Time of day \\
\hline \multirow{3}{*}{$\begin{array}{l}\text { Video-tape }{ }^{20-22} \\
\text { observation }+ \\
\text { computer-aided coding } \\
\text { by Noldus Observer }^{+}\end{array}$} & $\mathrm{NH}, \mathrm{ALF}$ & Varies $^{\S}$ & Inter-rater & Frequency \\
\hline & & & & Time of day \\
\hline & & & & Spatial disorientation \\
\hline
\end{tabular}

and inclusion of wandering outcomes (Table 1).

While a range of measurement methods have been used to study wandering, none are ideal and few target geographic or spatial aspects of wandering behavior. Observational methods, which offer the greatest detail, have been limited to institutional use and are restricted in capacity to studying mainly one individual at a time. Few measurement approaches capture information about all four aspects of wandering locomotion, i.e., frequency, repetitiveness, temporal distribution, and spatial disorientation. Many do not differentiate wandering from its outcomes, thus blurring an important conceptual and practical distinction. When it is necessary to capture the full complexity of wandering and its outcomes, multiple approaches applied simultaneously are required.

Observational studies have most frequently categorized wandering behaviors as random, lapping, and pacing ${ }^{23-26}$, spatial depictions that capture the geographic pattern or pathway traversed by wanderers. Specific observable behaviors illustrating the spatial nature of wandering and/or representing its other facets have been poorly articulated and rarely operationalized $^{27}$. Lingering and shadowing, two wandering behaviors commonly observed in clinical practice that occur proximate to exit doorways and other exit points, are of particular interest because clinicians report they can lead to exiting. The relationship of lingering and shadowing behaviors to one another and to eventual exiting by persons with dementia is unknown. However, it is clear that lingering and shadowing represent potentially hazardous spatial aspects of wandering. Consequently, development of measurement approaches for these two behaviors would greatly further our understanding of risky wandering and better inform safe care practices.

\section{RFID AND UWB-RFID}

Radio Frequency Identification Devices (RFID) such as Carewatch $®$ have routinely been applied to manage wandering in institutional care settings because they can discriminate among individuals and selectively alarm or secure portals contingent on the presence of a specific individual. RFID devices responsively broadcast an identification number when struck by encoded radio frequency emissions from a transponder device. The RFID may be unpowered or powered; unpowered RFID's operate over about a meter's distance, while powered RFID's may operate over hundreds of meters. The reception of the broadcasted number by the transponder provides the time of reception and the identity of the source. With multiple trans- 

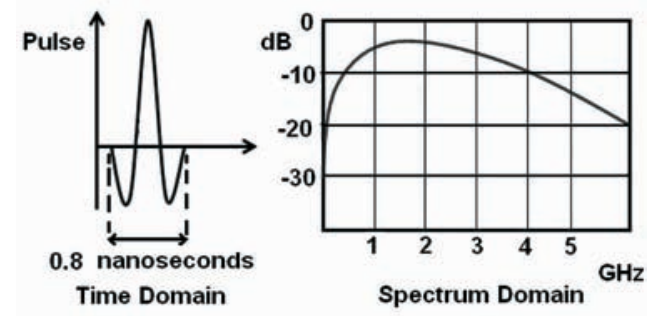

Figure 1: UWB-RFID pulse and bandwidth

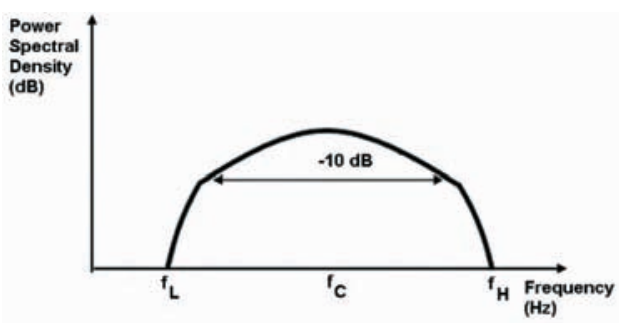

Figure 2: UWB-RFID fractional bandwidth

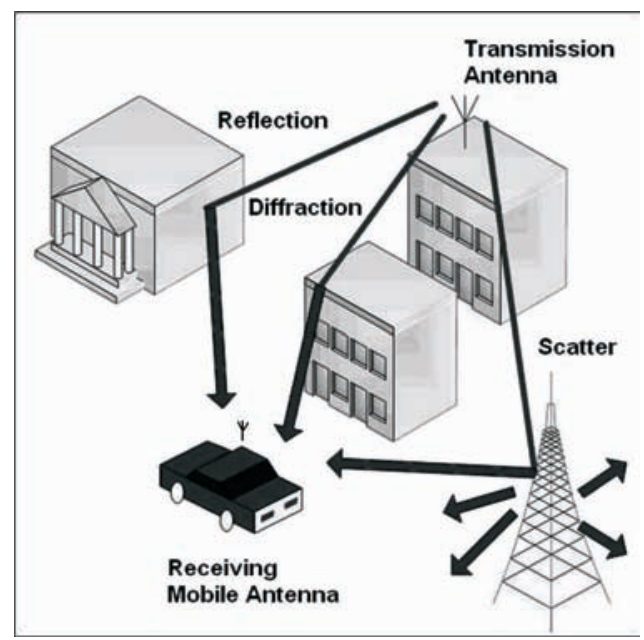

Figure 3: Reflection, diffraction and scattering in wireless medium

ponders an exact placement of the source within less than a few tens of centimeters can be achieved. A variant of RFID called Ultra Wideband offers advantages over passive RFID through its capacity to reveal the identity and precise locations of multiple persons moving simultaneously.

Ultra Wideband RFID is an ideal method for study of shadowing and lingering wandering behaviors due to its precise location and identification characteristics ${ }^{28,29}$. Traditional wireless communications ma- nipulate an information signal to place it on a high frequency carrier for propagation through the wireless medium. High carrier frequencies result in small antenna sizes since $\lambda$, the wavelength of propagating signal, is proportional to the antenna size and $\lambda=c / f_{c}$ (where $c$ is the speed of light in 299,792,458 meters per second and $f_{c}$ represents the carrier frequency). Ultra wideband radio transmission differs by sending sub-nanosecond (1 billionth of a second) pulses, known as impulse radio or IR, over bandwidth exceeding 500 $\mathrm{MHz}$ as declared by the US Federal Communications Commission, FCC. Since pulse widths are inversely proportional to bandwidth, transmitting short pulses results in transmissions over very large bandwidths. Thus ultra wideband eliminates the need for high frequency carrier waves in traditional wireless transmissions. Figure 1 depicts the UWB-RFID pulse and the corresponding signal in frequency.

The US FCC identifies any wireless transmission as UWB-RFID if the transmitted signal is equal or greater than $500 \mathrm{MHz}$ or the fractional bandwidth exceeds 0.2 . The fractional bandwidth is defined as 2 $x\left(F_{H}-F_{L}\right) /\left(F_{H}+F_{L}\right)$, where $F_{H}$ and $F_{L}$ are the upper and lower edge of frequencies, respectively ${ }^{30}$ (Figure 2 ).

\section{UWB-RFID operation}

Electromagnetic wave propagation between any two points is challenged by obstacles in its path. Obstacles may be moisture in the air or physical objects such as mountains, buildings, signal towers, or even furniture in a room. Electromagnetic waves striking these objects may reflect, diffract or scatter, producing more paths or rays than originally transmitted (Figure 3). The rays travel different paths, arriving with different delays at the receiver; UWB-RFID technology captures these paths which vary in magnitude and phase. The ability of UWB-RFID to gather signals crossing varied paths over time is a key 
advantage UWB-RFID technology holds over preceding RFID technologies.

\section{Key Features of UWB}

Ultra wideband confers several advantages to researchers on wandering: UWB-RFID can penetrate a wide variety of materials including the human body, walls, and earth. Transmissions can operate on unlicensed frequencies ranging from 3.1 to $10.6 \mathrm{GHz}$. This wide spectrum coverage comes with severe power restrictions imposed by the FCC which allows UWB-RFID to coexist with other technologies such as $802.11 \mathrm{a} / \mathrm{g}$ radio that share narrower bands within the UWB-RFID frequency range. The restricted power levels mean UWB-RFID signals may be treated as noise rather than an information signal by other devices. Low power levels mean that UWB devices can transmit data over periods of years without battery replacement. Different FCC power restrictions obtain for indoor and outdoor UWB-RFID transmission; and these limits vary according to the UWB-RFID frequency chosen for transmitting. UWB-RFID devices can be made inexpensively because they do not encode information signals on high frequency carrier waves and thus can use less expensive hardware. The large bandwidth available to UWB-RFID allows potentially very high data rate transmissions (on the order of 1Gbps) over very short ranges (less than $1 \mathrm{~m})^{30}$. UWB-RFID devices can trade off data rate against range, however, permitting transmission modes customized to the needs of the research application and local conditions.

\section{Sample applications}

UWB's unique features make it highly desirable for applications needing high data rate, low power, cost and complexity. Several current application areas include:

(i) Location Tracking: UWB can track a moving transmitter in real-time. Applications include collision avoidance vehicular radar systems, tracking military targets, inventory tracking and management, and patient tracking in hospital environments. (ii) Wireless Communication: High data rates and the short range of UWB-RFID make it suitable for wireless home networking of peripherals such as a mouse, keyboard, wireless USB, high speed wireless personal area networking (WPAN), wireless body area network (WBAN) etc.

(iii) Imaging: The high penetration capabilities of UWB confer significant advantages in imaging systems such as ground penetration radars, through-wall radar imaging, surveillance systems, medical imaging and imaging behind obstructions, potentially assisting firemen and public safety authorities.

\section{UWB-RFID for lingering and shadowing}

We identified five device specifications necessary for valid and reliable measures of lingering and shadowing: (i) Sensitivity specificity, (ii) Determination of subject identity, position and timing permitting differentiation of lingering and shadowing from other behaviors, (iii) Simultaneous tracking of single and tandem subject locomotion, (iv) Continuous measurement and data storage with minimum supervision, and (v) Unobtrusive appearance. These key specifications are detailed below.

Sensitivity specificity. The device must allow differentiation of lingering and shadowing behaviors from other behaviors both within and across subjects.

Precise detection of subject identity, position and timing. The device must differentiate subjects' identities and locations anywhere in the research area. Accuracy may not degrade due to interposed furniture, human bodies or other objects located between device and subjects.

Simultaneous tracking of single or tandem locomotion. The device must accurately and simultaneously track patterns of movement of subjects moving independently or in tandem and allow the calculation of the distance between them while moving. 


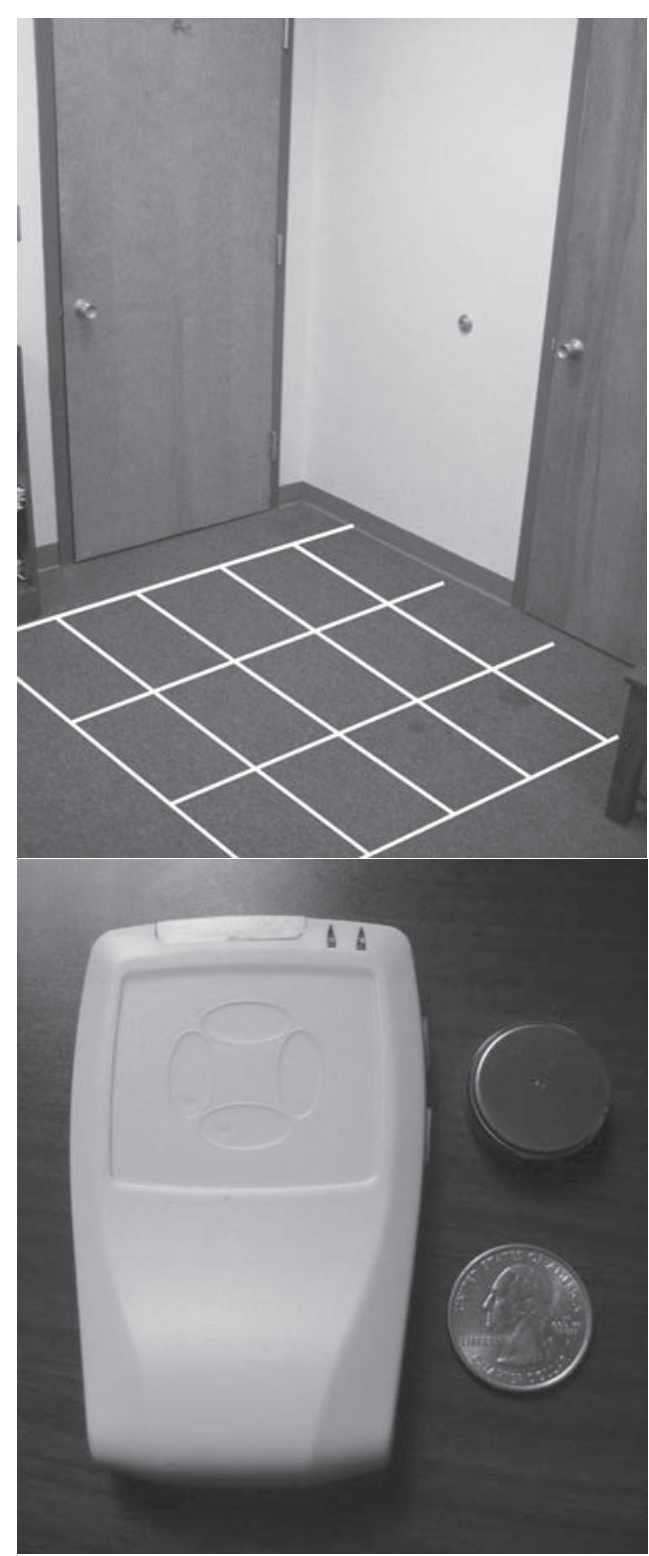

Figure 4: Laboratory test set-up; upper: Exit door and floor grid (uppermost line is $Y$ coordinate, leftmost line is X coordinate); lower: the $U W B-R F I D$ tag

Continuous observation and data storage. The device must continuously record and permanently store data with minimal researcher supervision; data extraction should be minimally disruptive of care setting occupants activities.

Unobtrusive. The UWB-RFID system components should blend unobtrusively into care setting décor to minimize potential effects on subject behavior. Tags worn by subjects should be small, lightweight, waterproof, impact resistant, produce no social stigma, and be maintenance free ${ }^{31}$.

The next section presents results from a laboratory study evaluating UWB-RFID's ability to detect lingering and shadowing behavior.

\section{THE TEST ENVIRONMENT}

Four UWB-RFID sensors were mounted at the corners of a room measuring 4.22 by $4.72 \mathrm{~m}$ and within $30.0 \mathrm{~cm}$ of the ceiling. The laboratory floor was split in four quadrants, and the length, width and center point measured to $0.1 \mathrm{~cm}$ accuracy. Figure 4 a displays quadrant number two near the exit door which was further calibrated into $(50 \mathrm{~cm} \times 50 \mathrm{~cm})$ squares.

A suboptimal feature of the test environment was the presence of twelve steel filing cabinets covering two walls of the laboratory space which were known to degrade UWB-RFID signals by inducing radio reflection. Our laboratory therefore represented a worst case UWB research environment for obtaining accurate measurements. Typically, institutional or house-based research sites would yield considerably more precise readings in the absence of noisy conditions such as those encountered in our laboratory. Figure 4 shows the wearable UWB-RFID transponder tag (Ubisense, Inc.) used in the tests compared to a US quarter and a battery cell. The UWB-RFID tags measured 5.8 $\mathrm{cm} \times 9.2 \mathrm{~cm} \times 1 \mathrm{~cm}$ and could be affixed to clothing via a plastic clip or a thin breakable lanyard looped about the neck. The UWB-RFID tag may transmit at an experimenter determined rate varying from $10 \mathrm{~s}^{-1}$ to once every several minutes and can boost its transmission rate contingent on tag movement. The signal received by the fixed wall sensors was fed through a conventional Ethernet switch to the network port of a PC containing UWB-RFID 
management software and a database for data storage (Ubisense, Inc).

\section{TEST PROTOCOL, RESULTS, DISCUSSION}

Two laboratory tests were conducted to determine absolute position accuracy and movement tracking of two tags simultaneously. $X, Y$, and $Z$ coordinates in centimeters were obtained from each tag referent to the laboratory's dimensions.

A single UWB-RFID tag was attached to a fixed height rotating platform spun at 120 rpm for 10 seconds at each of the 20 calibrated locations within the second quadrant of the laboratory floor. The obtained location data ( $\mathrm{X}, \mathrm{Y}$ coordinates) plotted using SPSS Version 15 appear in Figure 5. Predicted tag position appears as an asterisk and the obtained data appear as a circle. As may be seen, UWB-RFID yielded errors under $20 \mathrm{~cm}$ throughout the quadrant and improved as distance from the walls increased. Location errors were observed when the tag was not fully visible to a sensor positioned on a wall or doorway. An approach recommended by the vendor for reducing error around doorways was to install multiple sensors and incline them towards the doorway to improve cover- age. The small error observed at the center of the room may have been due to reflections of UWB-RFID signals as the tag approached the 12 steel cabinets lining the adjacent wall. Reducing the number of the steel obstacles in the room would greatly improve location accuracy at the room's center. The small systematic error that appears in the measurements is likely due to errors in measurement during the calibration procedure. Precise calibration of the room dimensions and the location coordinates of the sensors are equally important since the UWB-RFID positions are calculated with respect to the sensor location data and the input room dimension.

\section{Tracking test (shadowing)}

To test the UWB-RFID ability to measure 'shadowing', a tag was attached to each of two volunteer test subjects using the same experimental apparatus and setting. Subjects followed one another at a distance of approximately 1 meter simulating "shadowing" behavior. Location data were collected simultaneously from both tags at the rate of three times per second. Only the first 10 seconds of data are shown in Figure 6, the remaining 20 seconds data

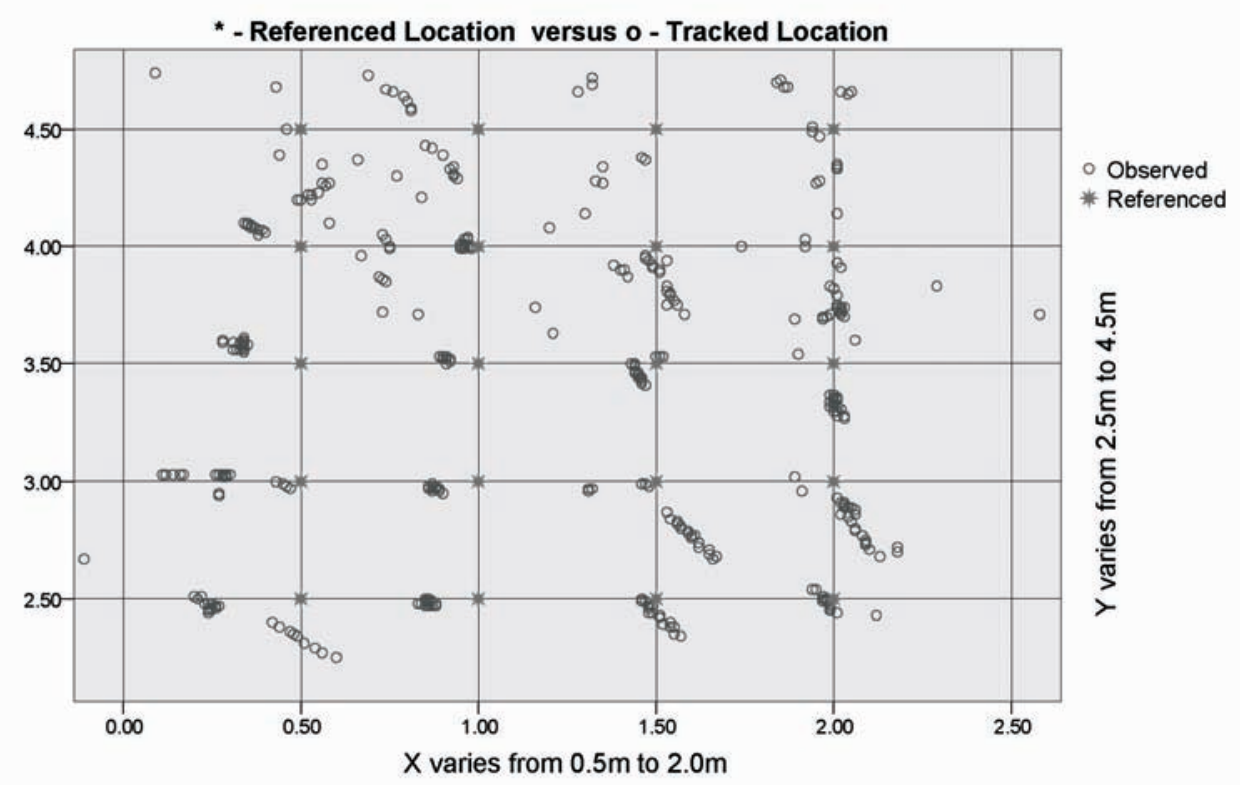

Figure 5: Plot of location data collected from UWB-RFID tag in quadrant 2 
were omitted for clarity of presentation. Data points represent the median $\mathrm{X}$ and $Y$ values for each second. The 'Caregiver' is represented by a triangle; the 'Patient' is represented by a circle. Each participant simultaneously moved clockwise around the grid, with the 'caregiver' beginning at approximately the 6 o'clock position (middle bottom) on the grid and ending roughly at a 3 o'clock position (upper right). The 'patient' began walking at approximately the 3 o'clock position slightly to the right of the grid at an X coordinate of 2.5 and ended at roughly the 11 o'clock position on the grid. The numbers co-located with each data point indicate their order of occurrence and correspond to each second of data. The data points for each individual are time-locked to their companion, so observation 1 for the 'caregiver' occurred at precisely the same instant as observation 1 for the 'patient', observation 2 for observation 2, etc.

The results of the analysis of all data showed that the mean inter-tag distance when both tags were in motion averaged $1.07 \mathrm{~m}$ with a SD of $0.48 \mathrm{~m}$ and an SEM of $0.089 \mathrm{~m}$. The tags diverged from 0.33 $\mathrm{m}$ to a maximum of $2.23 \mathrm{~m}$ during the test and the observations were normally distributed. Had the tags been attached to an actual caregiver/wanderer dyad moving through space in tandem and had a cutoff of $2 \mathrm{~m}$ inter-tag distance been used as a definition of 'shadowing', most observations would have been correctly classified as 'shadowing' behavior. It should be noted that during recording two data points for the 'patient' (points 7 and 8) fell to the left beyond the range of the grid. The points' coordinates, generated by the tag as it passed in close proximity to the wall of the room, were clearly erroneous since they would have required the tag to pass through the wall of the room. The parsimonious explanation for this error is that the 'patient' tag passed out of clear view of the sensor as it approached the wall and thus introduced error into the signal from the tag. A simple conditional statement excluding coordinates falling outside of the grid range would prevent such erroneous values from being included in the data analysis.

Our results clearly demonstrate the ability of ultra wideband RFID to simultaneously

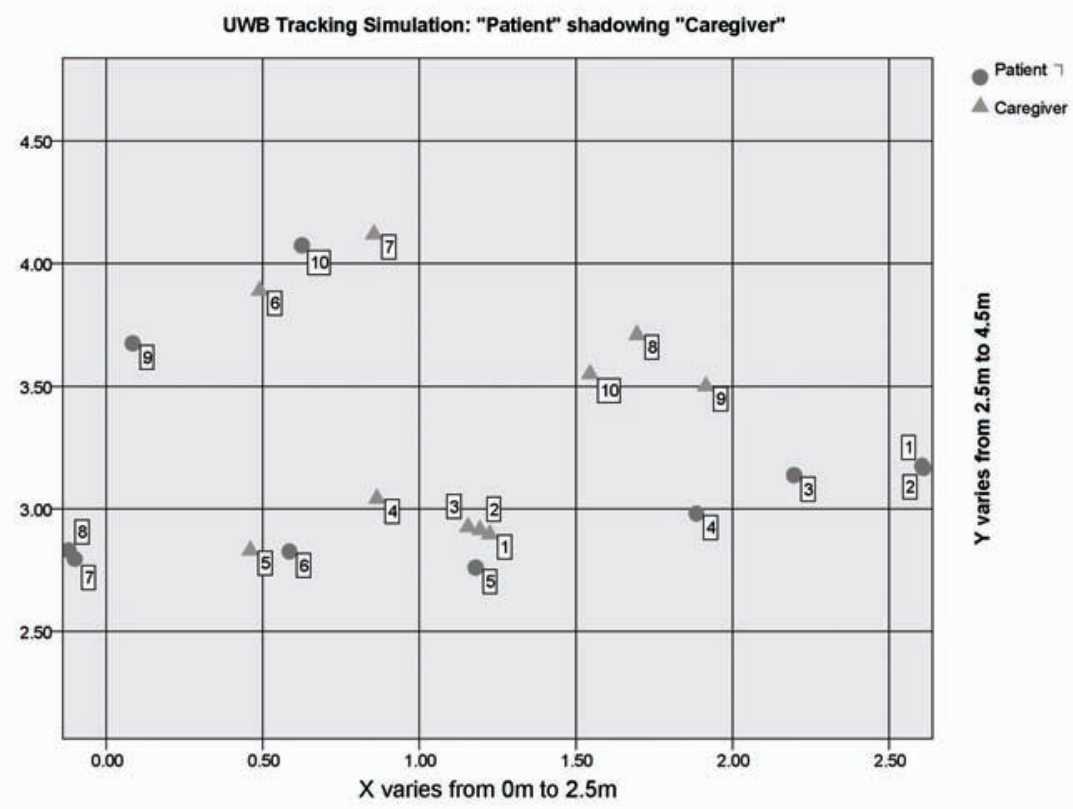

Figure 6: Plot of shadowing data from simulated 'caregiver' and 'patient' 
gather data on multiple individuals' locations in real-time and to precisely locate individuals to within $20 \mathrm{~cm}$. We have accrued over 180,000 measurements from a single tag over extended measurement intervals with minimal drift. The manufacturer (Ubisense, Inc) claims no upper limit on the number of tags which may be monitored simultaneously. We conclude from these tests that the UWB-RFID technology is sufficiently reliable and precise to permit accurate measurement of lingering and shadowing behavior and is capable of extended operations unattended. We are currently deploying our systems for homebased trials with persons with dementia who wander and their caregivers and we will report those findings as they become available.

\section{Future ReSEARCH}

We have provided data that point to Ultra Wideband Radio as a valid and reliable method to measure wandering in persons with dementia. Researchers who harness this technology are uniquely positioned to garner new knowledge on the antecedents and consequences of risky wandering, or wandering that occurs in spatial or geographic relationship to care setting exit points. This knowledge can critically inform effective, targeted applications of wandering management interventions designed to keep persons with dementia safe and secure in nursing home, community-based and home-based care settings. Interestingly, this same UWB-RFID technology suggests itself as a valuable tool to evaluate the efficacy of these wandering management interventions, to precisely measure the size of any effect on wandering behavior, and the consistency of the effect over time. To those concerned with the well-being of adults in the later stages of the lifespan, particularly those who have dementia and wander, we contend this represents a methodological breakthrough worthy of significant investigation.

\section{Acknowledgement}

This research was funded by the $2006 \mathrm{Na}$ tional Center for Patient Safety Initiative Program in Washington, D.C., and the James A. Haley Veterans Administration Hospital $\mathrm{Pa}$ tient Safety Center of Inquiry (JAHVA PSCI) in Tampa, Florida. The study was conducted at the JAHVA PSCI and the University of South Florida Department of Aging and Mental Health. The authors are members of the International Research Consortium on Wandering, and acknowledge Consortium support in the development and review of this manuscript.

\section{References}

1. Tierney L, McPhee S, Papadakis M. Dementia. Current Medical Diagnosis and Treatment, 38th edition. Stamford: Appleton and Lange; 1999

2. 2007 Alzheimer's disease facts and figures. Chicago: Alzheimer's Association; 2007

3. Algase D, Moore D, Vandeweerd C, Gavin-Dreschnack D. Mapping the maze of terms and definitions in dementia-related wandering. Aging \& Mental Health; in press

4. Cohen-Mansfield J, Werner P, Marx M, Freedman L. Two studies of pacing in the nursing home. Journal of Gerontology

\section{1;46(33):M77-M83}

5. Algase D, Struble L. Wandering: What, why \& how? In: Buckwalter K, editor. Geriatric Mental Health Nursing: Current and Future Challenges. Thorofare: Slack; 1992; pp 61-74

6. Rheaume Y, Riley M, Volicer L. Meeting nutritional needs of Alzheimer's patients who pace constantly. Journal of Nutrition for the Elderly 1987;7(1):43-52

7. Hope T, Keene J, Gedling K, Fairburn C, Jacoby R. Predictors of institutionalization for people with dementia living at home with a carer. International Journal of Geriatric Psychiatry 1998;13(10):682690

8. Gaugler J, Edwards A, Femia E, Zarit S, Stephens M, Townsend A, Greene R. Predictors of institutionalization of cognitively impaired elders: Family help and the timing of placement. Journal of Gerontology B Psychological Science Social Science 2000;55(4):247-255

9. McShane R, Gedling K, Keene J, Fairburn C, Jacoby R, Hope T. Getting lost in dementia: A longitudinal study of a behavioral symptom. International Psychogeriatrics 1998;10(3):253-260

10. Fulmer T, Paveza G, Vandeweerd C, Guadagno L, Fairchild S, Norman 
R, Abraham I, Bolton-Blatt M. Dyadic vulnerability and risk profiling for elder neglect. Gerontologist 2005;45(4):525534

11. Hamers J, Gulpers M, Strik W. Use of physical restraints with cognitively impaired nursing home residents. Journal of Advanced Nursing 2004;45(3):246-251

12. Lai C, Arthur D. Wandering behavior in people with dementia. Journal of Advanced Nursing 2003;44(1):73-182

13. Alzheimer's Association; 2007

14. Algase, D. A century of progress: Today's strategies for responding to wandering behavior. Journal of Gerontological Nursing 1992;18:28-34

15. Alzheimer's Association; 2007

16. Algase D, Beattie E, Bogue E, Yao, L. The Algase Wandering Scale: Initial psychometrics of a new caregiver reporting tool. American Journal of Alzheimer's Disease and Other Dementias 2001;16(3):141-152

17. Algase D, Beattie E, Song J, Milke D, Duffield C, Cowan B. Validation of the Algase Wandering Scale (Version 2) in a cross cultural sample. Aging \& Mental Health 2004;8(2):133-142

18. Algase D, Son G, Beattie E, Song J, Leitsch S, Yao L. The interrelatedness of wandering and wayfinding in a community sample of persons with dementia. Dementia and Geriatric Cognitive Disorders 2004;17(3):231-239

19. Algase D, Beattie E, Lietsch S, Beel-Bates C. Biomechanical activity devices to index wandering behavior. American Journal of Alzheimer's Disease and Other Dementias 2003;18(2):85-92

20. Cohen-Mansfield J, Werner P, Culpepper W, Wolfson M, Bickel E. Assessment of ambulatory behavior in nursing home residents who pace or wander: A comparison of four commercially available devices. Dementia \& Geriatric Cognitive Disorders 1997;8(6):359-365

21. Martino-Saltzman D, Blasch B, Morris $\mathrm{R}, \mathrm{McNeal} \mathrm{L}$. Travel behavior of nursing home residents perceived as wanderers and nonwanderers. The Gerontologist 1991;31(5):666-672
22. Lucero $M$, Hutchinson $S$, Leger-Krall $\mathrm{S}$, Wilson H. Wandering in Alzheimer's dementia patients. Clinical Nursing Research 1993;2(2):160-175

23. Algase D, Beattie E, Therrien B. Impact of cognitive impairment on wandering behavior. Western Journal of Nursing Research 2001;23(3):283-295

24. Algase D, Kupferschmid B, Beel-Bates C, Beattie, E. Estimates of stability of daily wandering behavior among cognitively impaired long-term care residents. Nursing Research 1997;46(3):172-178

25. Algase D, Beck C, Kolanowski A, Whall A, Berent S, Richards K, Beattie E. Needdriven dementia-compromised behavior: An alternative view of disruptive behavior. American Journal of Alzheimer's Disease 1996;11(6):10-19

26. Martino-Saltzman D, Blasch B, Morris $R, M c N e a l$ L. Travel behavior of nursing home residents perceived as wanderers and nonwanderers. Gerontologist 1991;31(5):666-672

27. Lucero, M. Intervention strategies for exit-seeking wandering behavior in dementia residents. American Journal of Alzheimer's Disease and Other Dementias 2002; 17(5):277-280

28. Becker C. A new game of leapfrog? UWB-RFID is rapidly changing the product-tracking process. Some say the technology--once costs drop--could displace bar-coding. Modern Healthcare 2004;34(28):38-40

29. Glabman M. Room for tracking. UWBRFID technology finds the way. Materials Management Health Care 2004;13(5):2636

30. Arslan $\mathrm{H}$, Benedetto M. Introduction to Ultra Wideband. In Arslan H, Chen Z, DiBenedetto $M$, editors. Ultra Wideband Wireless Communication. Hoboken: John Wiley; 2006; pp 1-9.

31. Kearns W, Rosenberg D, West L, Applegarth S. Attitudes and expectations of technologies to manage wandering behavior in persons with dementia. Gerontechnology 2007;6(2):89-101 